\title{
Differential Inhibition of the Rhythm and Amplitude of Acetylcholine-Dependent Contraction in the Murine Jejunum and Ileum In Vitro by Thiamin and Quinine
}

\author{
Atsuko Yamashita ${ }^{1}$, Nana Shimamoto ${ }^{1}$, Kyoko Morita ${ }^{1}$, Hasumi Sugiyama ${ }^{1}$, Shiho Tadakuma ${ }^{1}$, \\ Maki Kato ${ }^{1}$, Mari Kimoto ${ }^{1}$, Kazuo Toda ${ }^{2}$, Masato Ota ${ }^{1, *}$ \\ ${ }^{1}$ Laboratory of Anatomy, Physiology, and Food Biological Science, Department of Food and Nutrition, Japan Women's University, Tokyo, \\ Japan \\ ${ }^{2}$ Integrative Sensory Physiology, Graduate School of Biomedical Sciences, Nagasaki University, Nagasaki, Japan
}

Email address:

ootam@fc.jwu.ac.jp (M. Ota)

${ }^{*}$ Corresponding author

\section{To cite this article:}

Atsuko Yamashita, Nana Shimamoto, Kyoko Morita, Hasumi Sugiyama, Shiho Tadakuma, Maki Kato, Mari Kimoto, Kazuo Toda, Masato Ota. Differential Inhibition of the Rhythm and Amplitude of Acetylcholine-Dependent Contraction in the Murine Jejunum and Ileum In Vitro by Thiamin and Quinine. Journal of Food and Nutrition Sciences. Vol. 6, No. 5, 2018, pp. 115-122. doi: 10.11648/j.jfns.20180605.11

Received: July 5, 2018; Accepted: July 16, 2018; Published: October 22, 2018

\begin{abstract}
Previously, the effects of several bitter substances have been investigated in the contraction of the murine jejunum and ileum, reporting that these independently suppress the rhythm generation of the interstitial cells of Cajal. Recently, it was reported that thiamin, which binds to a bitter taste receptor, modifies the early phase of the ileum contraction, whereas the physiological effects on the rhythm and amplitude of jejunum and ileum contractions remain unclear. In this study, it was investigated the physiological effects of thiamin and quinine on the in vitro contraction of the murine jejunum and ileum using mice for all experiments. the periodic contraction of the jejunum was observed before the administration of acetylcholine (Ach) and other substances, and the tonic amplitudes induced by the substances. These bitter substances variably affect the Achinduced rhythmic contraction of the jejunum and ileum in vitro. In addition, quinine hydrochloride (Qui) and thiamin hydrochloride (Thi) variably affect the Ach-induced rhythmic contraction of the jejunum and ileum in vitro. Both Qui and Thi markedly increase the rhythmic contraction in the jejunum. Although Thi does not change the rhythmic contraction in the ileum, it gradually reduces the amplitude in the jejunum. Conversely, Qui gradually reduces the amplitude and almost inhibits the contraction in the jejunum. Furthermore, an antagonist of the adrenalin-beta3 receptor, SR59230A, enhances the Quiinduced inhibition of the contraction in the jejunum.
\end{abstract}

Keywords: Thiamin, Quinine, Small Intestine, Mouse

\section{Introduction}

The activity of pacemaker cells between and within the muscle layers account for the rhythmic contraction of the small intestine in the absence of the nerve and hormonal stimulation. Prior studies using the isolated intestinal tract have reported that the intrinsic pacemaker activity originates from the interstitial cells of Cajal (ICCs) of the Auerbach plexus [1-8]; therefore, the rhythmic gastrointestinal contraction is considered to be primarily regulated by ICCs without the involvement of motor neurons, hormones, or inflammatory mediators [1-8]. Recent studies have reported that the action of the smooth muscle cells (SMCs) is associated with ICCs and platelet-derived growth factor receptor-alpha (PDGFR $\alpha$ ) immunoreactive cells, creating an integrated unit called the SIP syncytium, to regulate their rhythmic contraction [9-13]. Both ICCs and gastrointestinal SMCs frequently express various gap junction proteins, such as connexin $(\mathrm{Cx}) 43$ and $\mathrm{Cx} 45$, which facilitate communication between ICCs and SMCs [14]. Reportedly, quinine, a known standard bitter substance and antimalarial drug, selectively blocks Cx36 and Cx50 junctional currents in a reversible and concentration-dependent manner and only 
moderately affects $\mathrm{Cx} 45$ but does not substantially block gap junctions comprising $\mathrm{Cx} 26, \mathrm{Cx} 32, \mathrm{Cx} 40$, and $\mathrm{Cx} 43[15,16]$. Thus, quinine offers a potentially useful method to block specific gap junction channels, including those between neurons that are formed by $\mathrm{Cx} 36, \mathrm{Cx} 45$, and $\mathrm{Cx} 50$ and could change the rhythmic contraction of the jejunum and ileum.

Acetylcholine (Ach) is the major excitatory neurotransmitter of the enteric nervous system (ENS), and its excitatory effect on intestinal smooth muscle in the GI tract is directly mediated through the M3 muscarinic-type cholinoceptor [17]. Norepinephrine release pre-synaptically acts to decrease the activity in the cholinergic nerves of ENS through the activation of the $\beta 2$-adrenoceptor subtype [18]. Furthermore, norepinephrine directly acts on the intestinal SMCs to induce relaxation through the activation of $\beta 3$ adrenoceptors [19]. Previously, the effects of several bitter substances have been investigated in the contraction of the murine jejunum and ileum, reporting that these suppress the rhythm generation of the ICCs independently. Magnolol, a Magnolia officinalis bark extract, induces the depolarization of pacemaker potentials through M2 and M3 muscarinic receptors in cultured ICCs [20]. Quercetin inhibits pacemaker potentials through nitric oxide/cGMP-dependent activation and transient receptor potential melastatin 7 / Anoctamin-1 (TRPM7/ANO1) channels in cultured ICCs [21]. In addition, caffeine inhibits nonselective cationic currents in ICCs from the murine jejunum and relaxes the smooth muscle through the actin depolymerization [22, 23]. Recently, it was reported that thiamin, which is known to binds to a bitter taste receptor, modifies the early phase of the ileum contraction [24], whereas the physiological effects of thiamin on the rhythm and amplitude of jejunum and ileum contractions remain unclear. Thus, this study aimed to elucidate the physiological effects of thiamin compared with quinine in the contraction of the murine jejunum and ileum.

\section{Materials and Methods}

\subsection{Mice}

In this study, ICR mice were used for all experiments in accordance with the guidelines of the Animal Care and Use Committee of Japan Women's University. All mice were housed in polycarbonate cages under a 12-h/12-h light/dark cycle with ad libitum access to food and water.

\subsection{Movement Analysis of the Jejunum}

For the preparation of in vitro studies, a 1-cm-long portion of the murine jejunum and ileum were isolated while keeping mice under barbiturate anesthesia (Nembutal, $20 \mathrm{mg} / \mathrm{kg}$, intraperitoneal injection). Then, the inner contents of the isolated jejunum and ileum were washed for three time with prewarmed Tyrode's solution $\left(37^{\circ} \mathrm{C}\right)$ and, subsequently, the isolated tissue fragment of the jejunum or ileum was fixed in a Magnus-type chamber filled with $\mathrm{O}_{2}$-saturated Tyrode's solution $\left(37^{\circ} \mathrm{C}\right)$, as described previously [24]. Next, the proximal end of the preparation was set upward and connected to a strain gage through a cotton thread (Daruma\#30; Yokoi, Osaka, Japan). Conversely, the distal end of the preparation was attached to the bottom of the chamber. The movement of the jejunum or ileum were amplified using a strain gage amplifier $(\times 100)$ and continuously recorded using a pen recorder (SS259F2; SEKONIK, Tokyo, Japan). Next, the movements of the jejunum and ileum were recorded for $120 \mathrm{~s}$ following the Ach administration. Ach solution $(300-\mu \mathrm{L}$ total volume, at the concentration of 10 or $100 \mathrm{ng} / \mathrm{mL}$ ) were topically administered into the jejunum or ileum preparation using an injection syringe. In this study, the baseline was identified as the bottom line of the periodic deflection immediately before the administration of Ach with or without several other substances.

\subsection{Bitter Taste Substances}

In this experiment, 100 and $1000 \mu \mathrm{M}$ thiamin hydrochloride (Thi) and $100 \mu \mathrm{M}$ quinine hydrochloride (Qui) (Wako Pure Chemical Industries, Japan) were used [24]. In addition, $100 \mu \mathrm{M}$ of $\beta 3$-adrenoceptor antagonist SR59230A (Sigma) was used in combination with Qui [25].

\subsection{Statistical Analysis}

In this study, data are expressed as the mean \pm standard error (SE). The Student's t-test is used to compare single values under control, and experimental conditions or the ANOVA followed by the Dunnett's post-hoc analysis to compare groups of data. $\mathrm{P}<0.05$ is considered as statistically significant. Of note, the $\mathrm{n}$ values indicate the number of samples used in the experiment.

\section{Results}

\subsection{The Rhythm Slowdown of the Ach-Induced Contraction of the Jejunum in a Dose-Dependent Manner}

The periodic contraction of the jejunum was observed before the administration of Ach and other substances, and the tonic amplitudes was induced by the substances (Figure 1). $10 \mathrm{ng} / \mathrm{mL}$ Ach (Ach10) induced periodic contractions of the jejunum in vitro (Figure 1). In addition, the amplitude of the periodic contraction (PA) and frequency of contraction were measured every $10 \mathrm{~s}$ to assess biological effects of bitter substances for the autonomous rhythm regulation in the jejunum (Figure 1). Furthermore, the amplitude (A), distance from the baseline to the bottom point of the periodic contraction, was measured to estimate the late response of the jejunum contraction. 


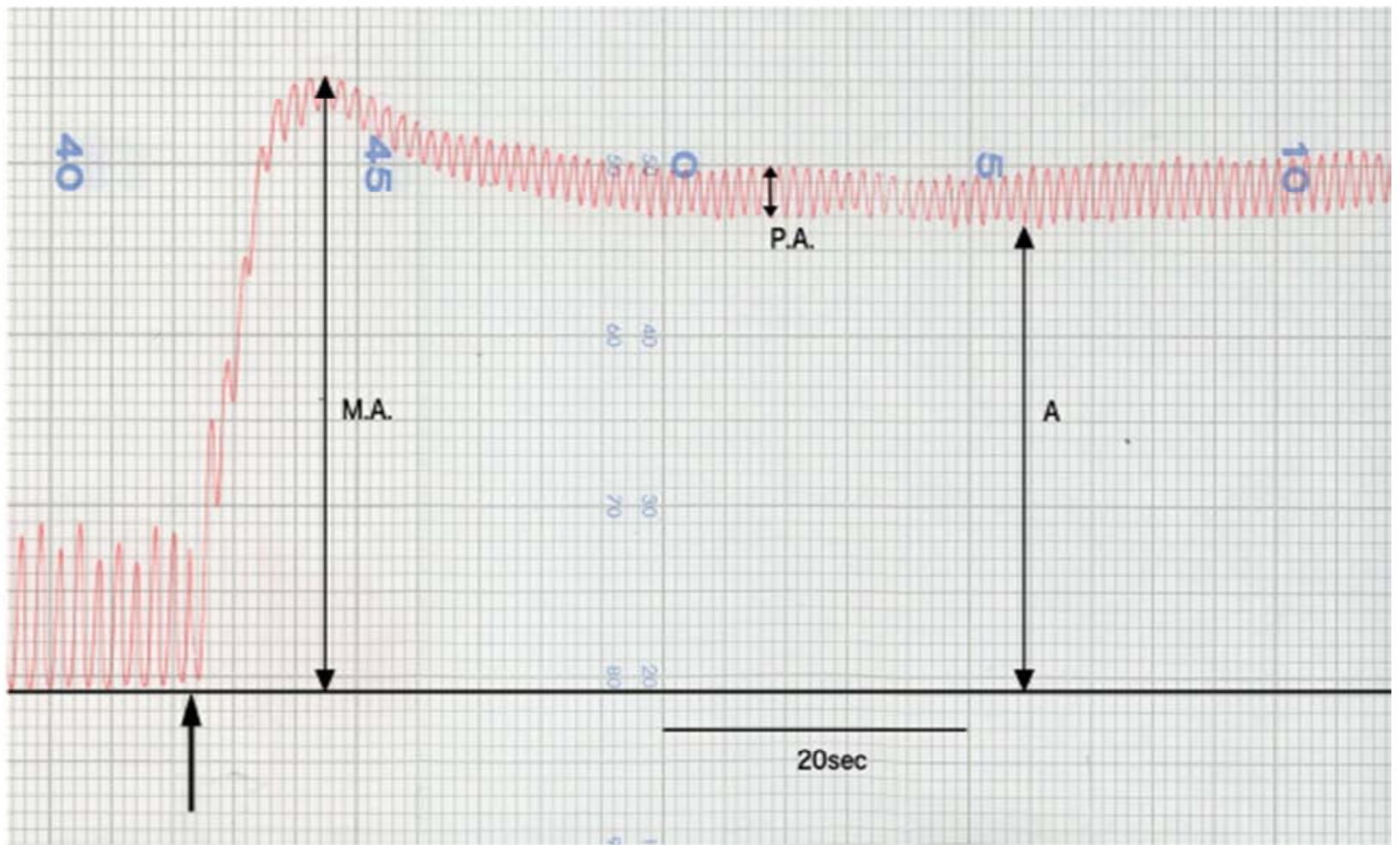

Figure 1. The typical example of the jejunum contraction induced by $10 \mathrm{ng} / \mathrm{mL}$ of acetylcholine (Ach). $10 \mathrm{ng} / \mathrm{mL}$ of Ach were administered into the tissue fragment of the jejunum (arrowhead), which induced incomplete tetanus (red line) during $20 \mathrm{~s}$ after the administration (black bar). The distance from the baseline (horizontal black line) to the inflection point of contraction (vertical double arrow) were considered as the MA. The periodic amplitude (PA; top vertical double-headed arrow) is defined as the periodic contraction range of the jejunum under the administration with or without other substances (vertical black line). The distance from the baseline to the bottom point of the periodic contraction (vertical double arrow) was considered the amplitude (A).

\subsection{Impact of Adrenaline and Bitter Substances on the Rhythm of Ach-Induced Contraction in the Jejunum}

The administration of $100 \mathrm{ng} / \mathrm{mL}$ Ach (Ach100) induced a tonic contraction of the jejunum (Figure $2 \mathrm{~A}$ ) and markedly slowed down the contraction rhythm of the jejunum during $60 \mathrm{~s}$ after the administration (Figure 3). The rhythm of Ach10-induced contraction was 4-6 $\times 10^{-1}$ times $/ \mathrm{s}$ in the jejunum and 3-4 $\times 10^{-1}$ times/s in the ileum (Figure $3 \mathrm{~A}$ ). Although Ach100-induced tetanus to disappear the contraction rhythm in the jejunum and ileum within $10 \mathrm{~min}$ after the administration, it partially and gradually reappeared in the jejunum. However, the loss of the contraction rhythm was continued for, at least, $60 \mathrm{~s}$ in the ileum (Figure 3B). In addition, $100 \mathrm{ng} / \mathrm{mL}$ adrenaline (Ad) recovered the rhythm of Ach100-induced contraction in the jejunum later than $40 \mathrm{~s}$ after the administration; however, it did not markedly impact

A

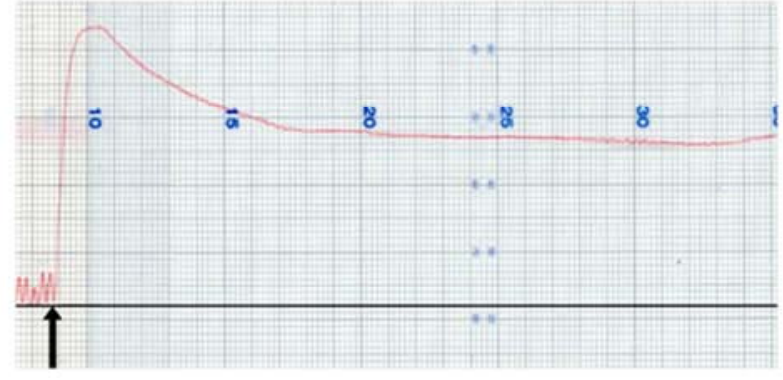

the rhythm in the ileum (Figures 2B and 3C). Moreover, 100 $\mu \mathrm{M}$ quinine (Qui), a bitter substance, recovered the contraction rhythm within $10 \mathrm{~s}$ after the administration in the jejunum, but not in the ileum (Figures 2A and 3D).

Unexpectedly, adrenergic receptor- $\beta 3$ antagonist, SR59230A, inhibited the Ach100-induced tonic contraction and maintained the contraction rhythm cooperatively with quinine (Figures 2B and 3E). Notably, $100 \mu \mathrm{M}$ thiamin (Thi100) prevented the disappearance of the contraction rhythm by Ach100 in the jejunum and ileum (Figures $2 \mathrm{E}$ and 3F). Furthermore, $1000 \mu \mathrm{M}$ thiamin (Thi1000) prevented the Ach100-induced tonic contraction in the jejunum and ileum (Figure 3G). Of note, the Ach100-induced contraction rhythm in the jejunum and ileum was maintained as almost constant in the presence of thiamin (Figures $2 \mathrm{E}$ and $3 \mathrm{~F}$ and G).

B

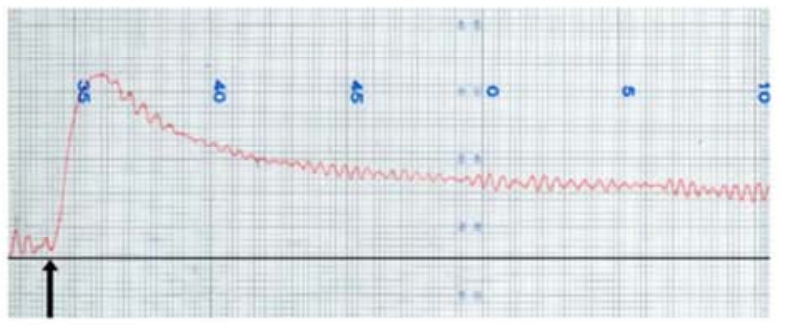


C

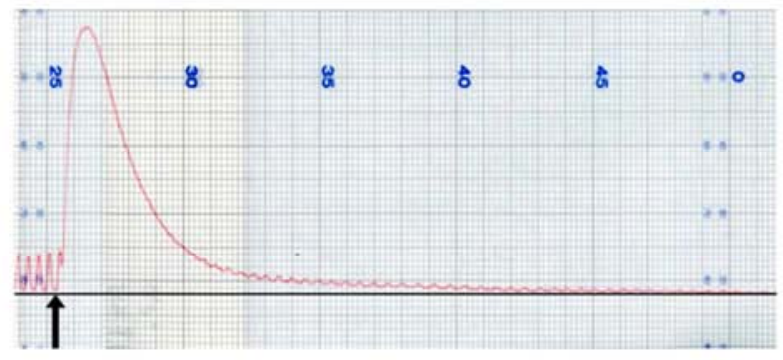

D

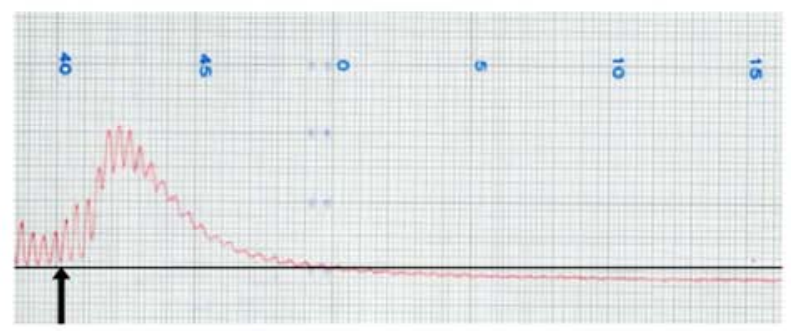

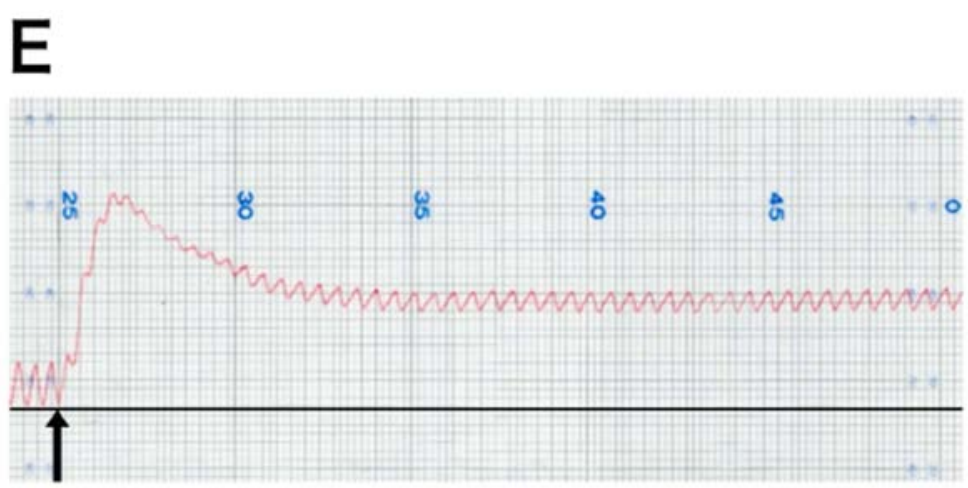

Figure 2. The typical pattern of the effects of the acetylcholine (Ach) application with or without other substances on the jejunum contraction. The application of $100 \mathrm{ng} / \mathrm{mL}$ of Ach (Ach100) solution (A) eliminated the generation of periodic contraction of the jejunum, but the administration of Ach100 with $100 \mathrm{ng} / \mathrm{mL}$ of adrenaline (Ad) solution restored it. (B) Ach100 solution with Qui (C) almost completely reduced until the baseline level. (D) Ach100 solution with Qui + SR59230A. (E) Ach100 with Thi100 reduced MA and restored the periodic contraction. The movement patterns (red line) were estimated using the baseline (horizontal black line) and the time of the Ach administration into the tissue fragment of the jejunum with or without other substances (arrowhead).

A

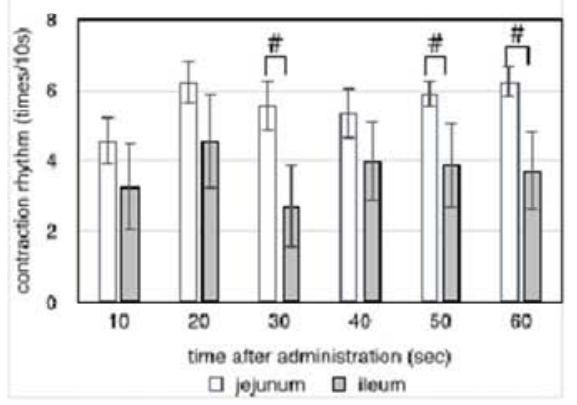

B

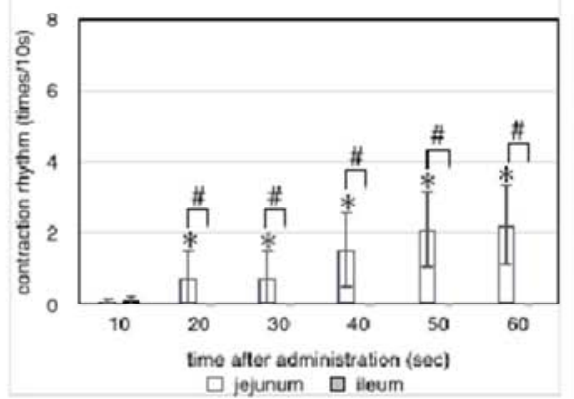

C

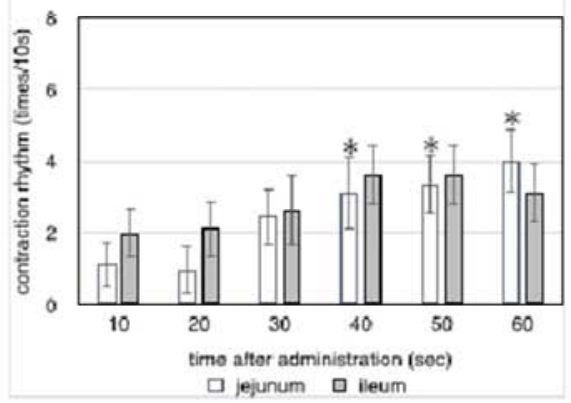

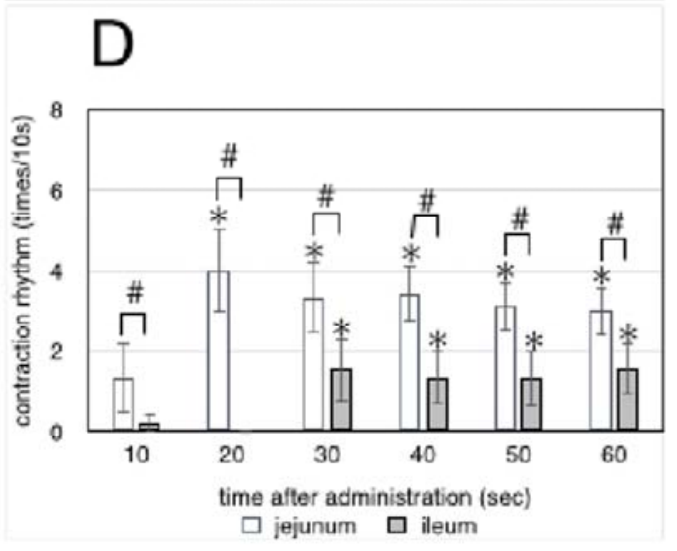

$\mathrm{E}$

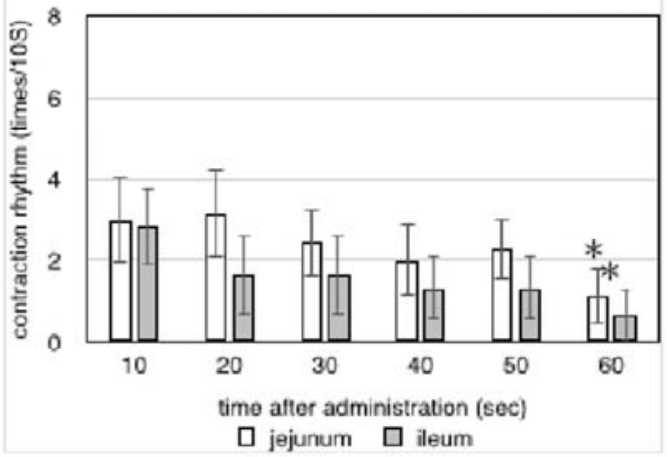



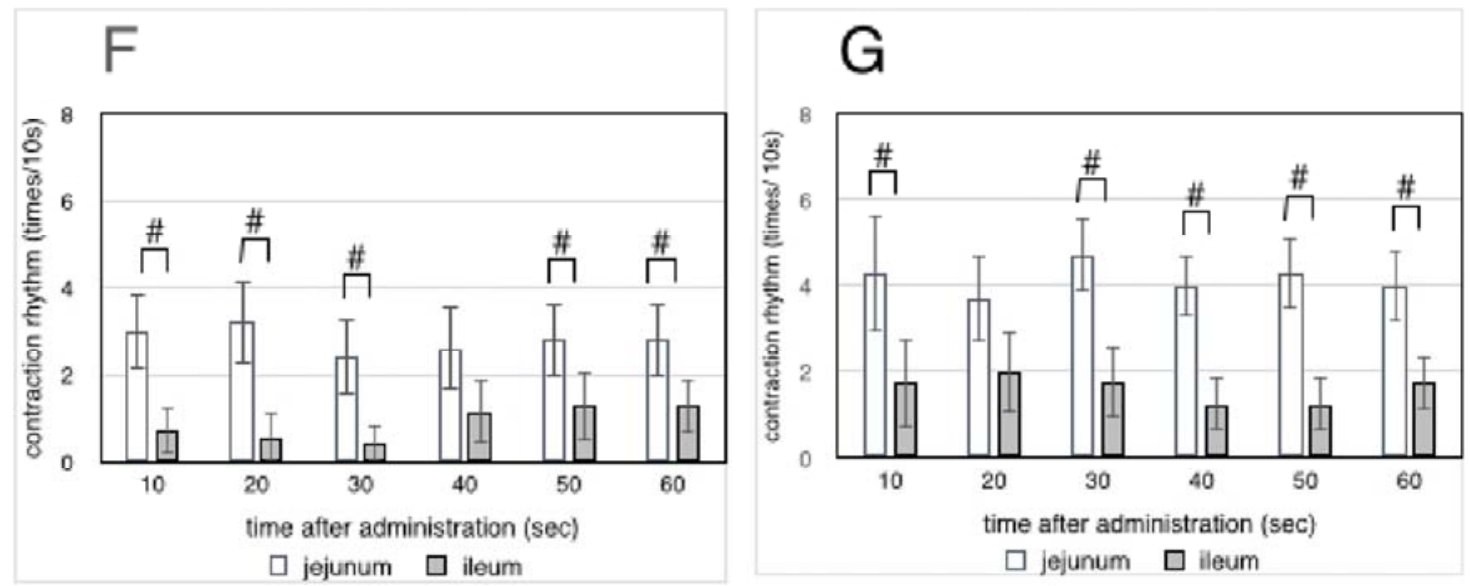

Figure 3. Adrenaline (Ad) and bitter substances affected the rhythm of acetylcholine (Ach)-induced contraction in the jejunum. The contraction rhythm of the Ach-induced contraction in the jejunum and ileum was counted every 10 min in each condition, such as Ach10 (A), Ach100 (B), Ach $100+A d(C), A c h 100+$ Qui (D), Ach100+Qui + SR59230A (E), Ach100 + Thi100 (F), and Ach100 + Thi1000 (G). The periods after every 10-s treatment were indicated as post $0-10$ s, post10-20s, post20-30s, post30-40s, post40-50s, and post50-60s. Error bars, standard error (SE). Each symbol (\#) indicated the significant difference ( $P<$ $0.05)$ between the jejunum (white boxes) and ileum (gray boxes). Each asterisk $*^{*}$ indicated the significant difference in the contraction rhythm $(P<0.05)$ between the beginning and later periods in the jejunum or the ileum.

\subsection{Thiamin, Not Quinine, Reduced the Maximum Amplitude of the Ach-Induced Contraction in the Jejunum}

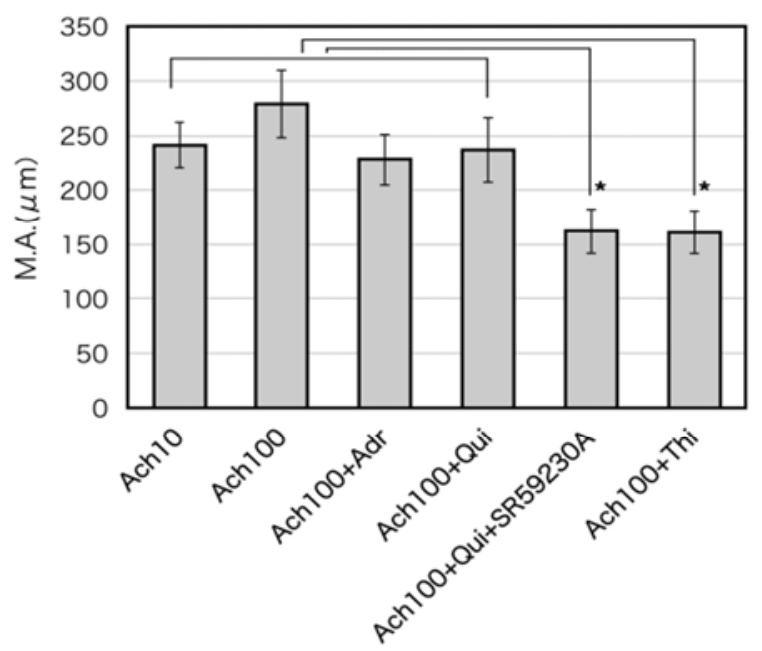

Figure 4. Thiamin, but not adrenaline (Ad) and quinine, decreased the $M A$ of the Ach-induced contraction of jejunum within $20 \mathrm{~s}$ after the administration. Remarkably, Qui did not significantly change the MA of Ach100 (P < 0.05); however, Qui reduced the MA of Ach100 $(P<0.05)$ in combination with SR59230A, an antagonist of the adrenalin- $\beta 3$ receptor. The MA of Ach10, Ach100, Ach100+Adr, Ach100 +Qui, Ach100 + Qui+ SR59230A, and Ach 100+ Thi were compared with each other. An asterisk (*) indicated a significant change in the MA of Ach100 $(P<0.05)$.

The significant decrease by Thi100 was observed in the MA of Ach10 and Ach100 (P< 0.05); however, the administration of Ad did not result in a significant change in the MA of Ach100 (Figure 4).

\subsection{Reduction of the Ach-Induced Contraction of the Jejunum by Bitter Substances After 20 s of Administration}

In this experiment, no significant changes were observed in the jejunum between Ach10 and Ach100 and between Ach100 and Ach $100+$ Ad from $20 \mathrm{~s}$ to $120 \mathrm{~s}$ after the administration (Figure 5). However, quinine markedly and gradually decreased to indicate the almost complete inhibition of the relative amplitude of the Ach-induced contraction in a timedependent manner. The administration of SR59230A enhanced the decrease of the Ach-induced contraction by Qui. In contrast, the relative contraction of the jejunum gradually changed later than $60 \mathrm{~s}$ after the Thi100 administration.

\section{Discussion}

This study demonstrated that bitter substances, quinine and thiamin, variably affect the Ach-induced rhythmic contraction of the jejunum and ileum in vitro. The rhythm and amplitude of the Ach-induced contraction of the jejunum and ileum are associated with, at least, ICCs within the nerve plexus and intestinal smooth muscle itself $[26,27]$. In this study, Qui transiently decreased the Ach-dependent rhythmic contraction of the jejunum and ileum but recovered 20-30 s after the administration; however, these early recoveries were not observed in combination with the $\beta 3$-adrenoceptor antagonist, SR59230A. A prior study using $\beta 3$-adrenoceptor knockout mice reported that $\beta 3$-adrenoceptors in the ileum are compensated by $\beta 1$-adrenoceptors [28], which are stimulated by noradrenaline to inhibit pacemaker currents in cultured ICCs from the murine small intestine [29]. This study suggested the functional interaction between Qui and $\beta 3$-adrenoceptors, although it warrants further investigation. 


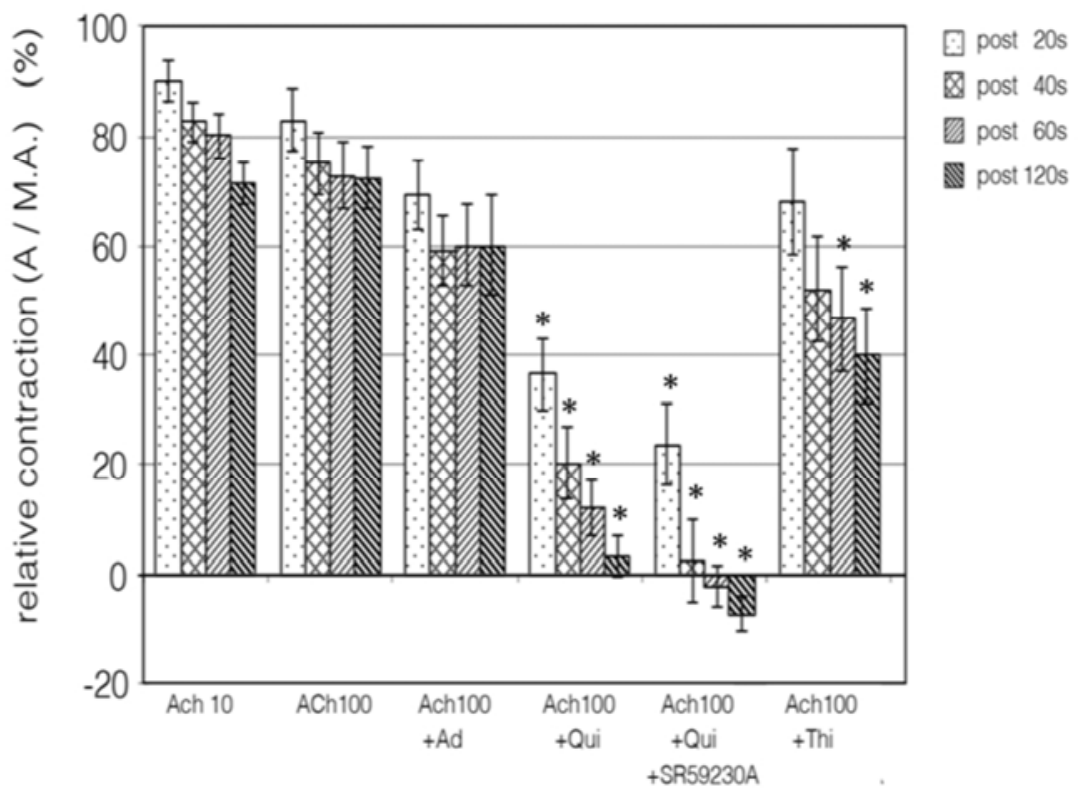

Figure 5. The ratio of each amplitude to the MA was estimated as a relative contraction of the jejunum while $120 \mathrm{~s}$ after the administration of each condition. Ach10, Ach100, Ach100+Adr, Ach100+Qui, Ach100+Qui+SR59230A, and Ach100+Thi were compared with each other. An asterisk (*) indicated a significant change in the MA of Ach100 $(P<0.05)$.

Recent studies on herbal medicines, such as Lizhong Tang and Dangkwisoo-san, reported that these modify the gastrointestinal motility or pacemaker activities of ICCs [30, 31]. In addition, some herbal extracts of the roots of ginger and Liriope Platyphylla Wang et Tang have been reported to mediate the contraction of the ileal smooth muscle in rats [32, 33]. Reportedly, naringenin, a citrus peel component, inhibits the pacemaking activity in ICCs [34]. In this study, it was observed that thiamin, a water-soluble substance of grain foods [35], increased the rhythmic contraction with the reduction of MA in the tissue fragment of the jejunum and ileum. A previous study using the smooth muscles of the gastric fundus and circular layer of the distal colon of guinea pigs reported that thiamin evoked depolarization in the smooth muscle strips as well as augmented the amplitude of inhibitory synaptic potentials and postinhibitory depolarization [36]. Furthermore, other studies suggested that thiamin is an integral component of synaptosomal membranes [37-40]. These findings suggested that thiamin plays a role in the mammalian neuromuscular transmission of ICCs to modulate contractions of the small intestine.

\section{Conclusion}

This study suggests that Qui and Thi variably affect the Achinduced rhythmic contraction of the jejunum and ileum in vitro. Both Qui and Thi markedly increase the rhythmic contraction in the jejunum. Although Thi does not change the rhythmic contraction in the ileum, it markedly reduces MA and gradually reduces the amplitude in the jejunum. Conversely, Qui does not markedly change MA and gradually reduces the amplitude and almost inhibits the contraction in the jejunum. Furthermore, an antagonist of the adrenalin- $\beta 3$ receptor, SR59230A, enhances the Qui-induced inhibition of contraction in the jejunum.

\section{Acknowledgements}

This work was supported by JSPS KAKENHI; grant numbers JP22592061 and JP17K08499.

\section{References}

[1] Sanders, K. M., Ward S. M., Koh, S. D. (2014). Interstitial cells: regulators of smooth muscle function. Physiol. Rev. 94:859-907.

[2] Huizinga, J. D., Chen, J. H. (2014). Interstitial cells of Cajal: update on basic and clinical science. Curr. Gastroenterol. Rep. $16: 363$.

[3] Lies, B., Gil, V., Groneberg, D., Seidler, B., Saur, D., Wischmeyer, E., Jiménez, M., Friebe, A. (2014). Interstitial cells of Cajal mediate nitrergic inhibitory neurotransmission in the murine gastrointestinal tract. Am. J. Physiol. Gastrointest. Liver Physiol. 307:G98-106.

[4] Al-Shboul, O. A. (2013). The importance of interstitial cells of cajal in the gastrointestinal tract. Saudi J. gastroenterol. 19 (1): 3.

[5] Lee, H. T., Hennig, G. W., Fleming, N. W., Keef, K. D., Spencer, N. J., Ward, S. M., Smith, T. K. (2007). The mechanism and spread of pacemaker activity through myenteric interstitial cells of Cajal in human small intestine. Gastroenterol. 132: 1852-1865.

[6] Farrugia, G. (2008). Interstitial cells of Cajal in health and disease. Neurogastroenterol. Motility, 20: 54-63.

[7] Garcia-Lopez, P., Garcia-Marin, V., Martínez-Murillo, R., Freire, M. (2009). Updating old ideas and recent advances regarding the Interstitial Cells of Cajal. Brain Res. Reviews, 61: 154-169. 
[8] Huizinga, J. D., Chen, J., Mikkelsen, H. B., Wang, X. Y., Parsons, S., Zhu, Y. (2013). Interstitial cells of Cajal, from structure to function. Front. neurosci. 7:43.

[9] Blair, P. J., Rhee, P. L., Sanders, K. M., Ward, S. M. (2014). The significance of interstitial cells in neurogastroenterology. J. Neurogastroenterol. Motil. 20: 294-317.

[10] Baker, S. A., Drumm, B. T., Skowronek, K. E., Rembetski, B. E., Peri, L. E. Hennig, G. W., Perrino, B. A., Sanders, K. M. (2018). Excitatory Neuronal Responses of $\mathrm{Ca}^{2+}$ Transients in Interstitial Cells of Cajal in the Small Intestine. eNeuro. 5: 0080-18.

[11] Sanders, K. M., Koh, S. D., Ro, S., Ward, S. M. (2012). Regulation of gastrointestinal motility- insights from smooth muscle biology. Nature Reviews: Gastroenterol. Hepatol. 9: 633-645.

[12] Koh, S. D., Ward, S. M., Sanders, K. M. (2012). Ionic conductances regulating the excitability of colonic smooth muscles. Neurogastroenterol. Motil. 24: 705-718.

[13] Hanani, M., Farrugia, G., Komuro, T. (2005). Intercellular coupling of interstitial cells of Cajal in the digestive tract. Int. Rev. Cytol. 242: 249-282.

[14] Seki, K., Komuro, T. (2001). Immunocytochemical demonstration of the gap junction proteins connexin 43 and connexin 45 in the musculature of the rat small intestine. Cell Tissue Res. 306: 417-422.

[15] Miduturu, S., Hoppersta, M. G., Spray, D. C. (2001). Quinine blocks specific gap junction channel subtypes. Proc. Natl. Acad. Sci. USA. 98: 10942-10947.

[16] Gajda, Z., Szupera, Z., Blazsó, G., Szente, M. (2005). Quinine, a blocker of neuronal cx36 channels, suppresses seizure activity in rat neocortex in vivo. Epilepsia. 46: 1581-1591.

[17] Uchiyama, T., Chess-Williams, R. (2004). Muscarinic receptor subtypes of the bladder and gastrointestinal tract. J. Smooth Muscle Res. 40: 237-247.

[18] Stephens, G. J., Mochida, S. (2005). G protein $\beta$ subunits mediate presynaptic inhibition of transmitter release from rat superior cervical ganglion neurones in culture. J. Physiol 563: $765-776$.

[19] Tanaka, Y., Horinouchi, T., Koike, K. (2005). Newinsightsinto $\beta$-adrenoceptorsin smooth muscle: distribution of receptor subtypes and molecular mechanisms triggering muscle relaxation. Clin. Exp. Pharmacol. Physiol. 32: $503-514$.

[20] Kim, H. J., Han, T., Kim, Y. T., So, I., Kim, B. J. (2017). Magnolia Officinalis Bark Extract Induces Depolarization of Pacemaker Potentials Through M2 and M3 Muscarinic Receptors in Cultured Murine Small Intestine Interstitial Cells of Cajal. Cell. Physiol. Biochem. 43: 1790-1802.

[21] Gim, H., Nam, J. H., Lee, S., Shim, J. H., Kim, H. J., Ha, K. T., Kim, B. J. (2015). Quercetin inhibits pacemaker potentials via nitric oxide/cGMP-dependent activation and TRPM7/ANO1 channels in cultured interstitial cells of Cajal from mouse small intestine. Cell. Physiol. Biochem. 35: $2422-2436$

[22] Jin, N. G., Koh, S. D., Sanders, K. M. (2009). Caffeine inhibits nonselective cationic currents in interstitial cells of Cajal from the murine jejunum. Amer. J. Physiol. Cell Physiol.

\section{7: C971-C978.}

[23] Tazzeo, T. Bates, G. Roman, H. N. Lauzon, A. M. Khasnis, M. D. Eto, M. Janssen, L. J. (2012) Caffeine relaxes smooth muscle through actin depolymerization. Amer. J. Physiol. Lung. Cell Mol. Physiol. 303: L334-42.

[24] Yamashita, A., Shimamoto, N., Morita, K., Sugiyama, H., Kimoto, M., Toda, K., Ota M. (2018) Thiamin and Quinine Differently Inhibit the Early Phase of AcetylcholineDependent Contraction of Mouse Ileum in vitro. Int. J. Nutr. Food Sci. 7: 94-99.

[25] Wu, M. J., Shin, D. H., Kim, M. Y., Park, C. G., Kim, Y. D., Lee, J., Park, I. K., Choi, S., So, I., Park, J. S., Jun, J. Y. (2015). Functional effects of $\beta 3$-adrenoceptor on pacemaker activity in interstitial cells of Cajal from the mouse colon. Eur. J. Pharmacol. 754:32-40.

[26] Goyal, R. K., Chaudhury, A. (2010). Mounting evidence against the role of ICC in neurotransmission to smooth muscle in the gut. Am. J. Physiol. Gastrointest. Liver Physiol. 298: G10-3.

[27] Klein, S., Seidler, B., Kettenberger, A., Sibaev, A., Rohn, M., Feil, R., Allescher, H. D., Vanderwinden, J. M., Hofmann, F., Schemann, M., Rad, R., Storr, M. A., Schmid, R. M., Schneider, G., Saur, D. (2013). Interstitial cells of Cajal integrate excitatory and inhibitory neurotransmission with intestinal slow-wave activity. Nat. Commun. 4: 1630.

[28] Hutchinson, D. S., Evans, B. A., Summers R. J. (2001). Beta (1)-Adrenoceptors compensate for beta (3)-adrenoceptors in ileum from beta (3)-adrenoceptor knock-out mice. Br. J. Pharmacol. 132: 433-42.

[29] Jun, J. Y., Choi, S., Yeum, C. H., Chang, I. Y., Park, C. K., Kim, M. Y., Kong, I. D., So, I., Kim, K. W., You H. J. (2004). Noradrenaline inhibits pacemaker currents through stimulation of $\beta 1$ - adrenoceptors in cultured interstitial cells of Cajal from murine small intestine. Br. J. pharmacol. 141: 670-677.

[30] Lee, M. C., Ha, W., Park, J., Kim, J., Jung, Y., Kim, B. J. (2016). Effects of Lizhong Tang on gastrointestinal motility in mice. World J. gastroenterol. 22: 7778.

[31] Sung, S. K., Kim, S. J., Ahn, T. S., Hong, N. R., Park, H. S., Kwon, Y. K., Kim, B. J. (2015). Effects of Dangkwisoo-san, a traditional herbal medicine for treating pain and blood stagnation, on the pacemaker activities of cultured interstitial cells of Cajal. Mol. Med. Reports. 12: 6370-6376.

[32] Jalali-Nezhad, A. A., Frajan-Mahhadi, F., Komeili, G., Barkhordari-Ahmadi, F. (2015) The effect of ginger hydroalcholicextract on rat ileal contraction in vitro. Zahedan J. Res. Med. Sci. 15:29-33.

[33] Kim, H. J., Park, S. Y., Kim, D. G., Park, S. H., Lee, H., Hwang, D. Y., Kim, B. J. (2016). Effects of the roots of Liriope Platyphylla Wang Et tang on gastrointestinal motility function. J. Ethnopharmacol., 184: 144-153.

[34] Kim, H. J., Kim, B. J. (2017). Naringenin inhibits pacemaking activity in interstitial cells of Cajal from murine small intestine. Integrative Med. Res, 6:149-155.

[35] Sharma, S., Sheehy, T., Kolonel, L. N. (2013). Ethnic differences in grains consumption and their contribution to intake of B-vitamins: results of the Multiethnic Cohort Study. Nutr. J. 12: 65. 
[36] Romanenko, A. V., Gnatenko, V. M., Vladimirova, I. A. (1994). Effect of thiamin on neuromuscular transmission in smooth muscles. Neurophysiol. 26: 370-377.

[37] Bettendorff, L., Wins, P. (2013). Biological functions of thiamin derivatives: Focus on non-coenzyme roles. OA Biochem., 1:10.

[38] Waldenlind, L. (1979). Possible role of thiamin in neuromuscular transmission. Acta Physiol. Scand. 105:1-10.
[39] Manzetti, S., Zhang, J., van der Spoel, D. (2014). Thiamin function, metabolism, uptake, and transport. Biochemistry. 53:821-35.

[40] Brown, G. (2014). Defects of thiamine transport and metabolism. J. Inherit. Metab. Dis. 37:577-85. 